\title{
Uma discussão sobre a definição de trapézio por meio do Software Geogebra
}

\author{
A discussion on the definition of trapeze by Geogebra Software
}

\author{
Liana Krakecker \\ lia.krake@gmail.com \\ Sonia Maria Burigato \\ soniaburigato@gmail.com \\ Cíntia Melo dos Santos \\ cintiamelos@hotmail.com
}

\begin{abstract}
Resumo
Este artigo trata de uma experimentação realizada com quatro alunos, mestrandos de um Programa de Pós-Graduação em Educação Matemática, cuja intenção foi investigar possibilidades de aprendizagem por meio de um processo cooperativo utilizando para isso o software Geogebra. O estudo teve como aporte teórico e metodológico concepções de Valente (2005), Scherer (2015) e Piaget (1977), referentes à aprendizagem cooperativa, as quais nortearam discussões, elaboração e adaptação de atividades com o uso das Tecnologias Digitais de Informação e Comunicação (TDIC), bem como, a construção do conhecimento em um processo cooperativo. A experimentação evidenciou diversos momentos de cooperação entre os participantes.
\end{abstract}

Palavras-chave: Tecnologia; Ensino de matemática; Cooperação; Geogebra.

\begin{abstract}
This article refers to an experiment carried out with four students, master of a Postgraduate Program in Mathematics Education, whose intention was to investigate learning possibilities through a cooperative process using Geogebra software. The study had as theoretical and methodological contribution, concepts of Valente (2005), Scherer (2015) and Piaget (1977), about cooperative learning, which guided discussions, elaboration and adaptation of activities with the use of Digital Information Technologies and Communication (TDIC), as well as, the construction of knowledge in a cooperative process. The experimentation evidenced several moments of cooperation between the participants.
\end{abstract}

Keywords: Technology; Mathematics teaching; Cooperation; Geogebra.

\section{Introdução}

Discutiremos, neste texto, a realização de uma atividade implementada com quatro professores/alunos do Programa de Pós-Graduação em Educação Matemática do INMA/UFMS sob a perspectiva da aprendizagem como um processo de cooperação conforme Piaget (1977).

Quando se trata da cooperação, no sentido que aqui estamos tratando, é importante a elaboração de situações que favoreçam o aluno à uma atuação ativa no processo do aprender, sendo ele mesmo o responsável pela construção do seu conhecimento. E neste processo, a 
interação com o outro, seja um colega ou com o computador, pode favorecer aspectos importantes para suas aprendizagens.

A sociedade atual necessita que os indivíduos sejam criativos, com capacidade de argumentar, e de "pensar, aprender sobre aprender, trabalhar em grupo e conhecer seus próprios potenciais" (VALENTE, 1999, p. 98). Estes são aspectos importantes e que também precisam ser trabalhados nas escolas.

A Matemática é rica em possibilidades de se justificar, argumentar, provar, estabelecer relações, dentre outros. Atividades que envolvem geometria, particularmente, geralmente possuem várias maneiras de resolução, caminhos que possibilitam abordar diversos conceitos além daqueles pensados anteriormente pelo professor. A exploração das diferentes possibilidades de resolução pode fazer com que os alunos aprendam uns com os outros, discutam respostas diferentes, identifiquem, expliquem e corrijam erros ou incoerências, enfim.

A utilização de um software que favoreça uma atividade com tais características, mostra-se pertinente para o trabalho em sala de aula, já que favorece a utilização de diversos conceitos, assim como, diferentes modos de se chegar às respostas. Em seguida, detalhamos e justificamos nossas escolhas em função de tudo que argumentamos até aqui.

\section{Cooperação na perspectiva de Piaget}

A nossa sociedade está em constante mudança e se encontra cada vez mais plural, participativa, solidária, integradora, e isso tem acarretado numa diversidade no modo como os alunos estão adquirindo seu próprio conhecimento. A função da escola é de ter e criar um ambiente social, que possibilite a criança se relacionar com o outro e com o conhecimento e que vise à inserção do cidadão na sociedade, favorecendo a informação e a criticidade para que saibam compreender e atuar no mundo que vive.

Entendemos que o professor é o protagonista nesse contexto, devendo preparar e promover aulas que despertem o interesse do educando, que agucem as suas curiosidades com temáticas e materiais didáticos que lhe sejam atraentes ou desafiadoras. Com a evolução das telecomunicações, utilização dos computadores, o advento da internet e o desenvolvimento das tecnologias, as Tecnologias Digitais de Informação e Comunicação (TDIC), ganharam destaque. Segundo Ponte, Oliveira e Varanda (2003), estas constituem tanto um meio fundamental de acesso à informação (Internet, bases de dados) como um instrumento de transformação da informação e de produção de nova informação, além de constituírem um importante meio de comunicação a distância e uma ferramenta para o trabalho colaborativo, permitindo o envio de mensagens, documentos, vídeos e software entre quaisquer dois pontos do mundo. 
No contexto escolar, estes autores afirmam que o uso das TDIC pode vir a contribuir para a constituição de uma educação mais adequada a sociedade atual das seguintes maneiras: colaborando com a aprendizagem de diversos conteúdos; possibilitando a criação de espaços de integração e comunicação; permitindo novas formas de expressão criativa, de realização de projetos e reflexões críticas, sendo um instrumento importante para a resolução de problemas.

$\mathrm{Na}$ Educação Matemática as TDIC foram inicialmente introduzidas para dinamizar e aumentar o interesse e a busca do conhecimento por parte do aluno. Os educadores matemáticos reconhecem nas TDIC, quando selecionadas e utilizadas adequadamente, um potente recurso didático para criar novas relações entre o aprendiz e o objeto do conhecimento, podendo até mesmo, ser usado como meio de lutar contra o insucesso escolar, permitindo aos alunos revelar melhor seus talentos, além de facilitar o acesso às informações, bem como, possibilitar a construção do conhecimento.

Para Piaget o conhecimento é concebido como uma construção, de maneira que essa construção pode ser explicada por meio do processo de abstração reflexionante. A abstração significa retirar, arrancar, extrair algo, ou seja, o processo de conhecimento está restrito ao que o sujeito pode retirar, isto é, assimilar dos observáveis ou não-observáveis. O sujeito só conhece um objeto enquanto age sobre ele, este caminho encontra-se permeado de desequilíbrios, devidos aos conflitos entre sujeito e o objeto por acomodação insuficiente, buscando assim o equilíbrio. É na procura pelo equilíbrio que o sujeito aprende, como aponta Scherer (2005):

É neste processo de busca pelo equilíbrio, ao compreender e apreender a novidade, acomodando o desconhecido ao que é conhecido, que o sujeito aprende. Ele coopera, opera mentalmente com e sobre as suas certezas, e com e sobre as certezas de outros e do meio, busca o equilíbrio, que é sempre provisório, pois deixa de existir ao surgir um novo desequilíbrio. (SCHERER, 2005, p.89)

$\mathrm{Na}$ educação o desequilíbrio é um processo essencial para desencadear a aprendizagem. Para isso são necessários questionamentos desafiadores os quais desequilibrem cognitivamente o aluno, deixando-o agir e promovendo espaços que resultem em cooperação externa e cooperação interna entre os sujeitos por meio de uma ação dialógica, todos envolvidos em uma ação comunicativa, resultando assim, em um movimento de aprendizagem cooperativa.

Esse desequilíbrio, que gera o movimento de cooperação interna e externa, pode ser causado pelos materiais entregues aos alunos, bem como pelos questionamentos realizados pelo professor ou demais colegas. Nesse contexto, pensando a educação em um processo cooperativo, de acordo com Piaget, existem três condições a serem satisfeitas, a saber: uma escala comum de valores intelectuais entre os sujeitos envolvidos; a justificação de uma 
afirmação sem contradizer-se e uma reciprocidade de pensamento. O domínio de validade destas, além de professor e aluno, estende-se para grupos maiores.

Além disso, é necessário que ocorra a aceitação (diferente de tolerância) e respeito mútuo em relação às ideias do outro, bem como a exposição dos diferentes pontos de vista. A cooperação (que pode ser interna e também externa) supõe, portanto, liberdade de pensamento, moral e política. E nisso tudo, estão inscritas proposições iguais, complementares e diferentes. Sendo estas últimas importantes para o debate, a exposição, entre outros, uma vez que necessitam de um acordo entre os envolvidos, como menciona Scherer (2005):

\footnotetext{
A cooperação proporcionada pelo agir comunicativo só acontecerá se o grupo conseguir coordenar seus pontos de vista, usando palavras com sentido conhecido por todos ou definindo-as no campo comum ao grupo, apresentando argumentos para as suas proposições, e sendo responsáveis em relação aos seus parceiros de discussão. (SCHERER, 2005, p. 92)
}

A cooperação deixa de acontecer se faltar reciprocidade entre os envolvidos, respeito mútuo, ou quando um dos participantes partir da ideia de que o seu ponto de vista é o único possível. É necessário destacar que, aqui, a cooperação diferencia-se da colaboração. A primeira, exige que se habite o ambiente, interagindo e operando com o outro. Quanto à colaboração, trata-se de ações mais isoladas, sem necessariamente trabalhar com o outro. Logo, o desafio do trabalho com as TDIC é que este seja pautado nessa aprendizagem cooperativa e que a participação de cada sujeito favoreça tanto coordenações externas quanto internas.

Assim, a cooperação acontece na reciprocidade entre os envolvidos, no respeito entre os pares e possibilita a autonomia entre os sujeitos. Porém é importante distinguir consenso com equilíbrio nas discussões do grupo, para que não recaiam em falsos equilíbrios.

No presente artigo, relatamos uma experiência de um trabalho cooperativo, com uso do software Geogebra. Para tanto, temos a compreensão de que a aprendizagem não ocorre somente colocando o aprendiz na frente do computador. É preciso pensar em atividades que favoreçam a participação ativa do mesmo.

Portanto, a metodologia para o ensino de Matemática por meio das TDIC proporciona ao professor trabalhar em sala de aula em diferentes contextos e tem favorecido significativos avanços na compreensão de conceitos e conteúdos matemáticos e no aprimoramento da prática docente pelo professor. Mesmo assim, este precisa ficar atendo às opções que faz, pois é necessário verificar se elas coadunam com os objetivos de ensino e aprendizagem que ele está planejando. Neste sentido, a escolha da tecnologia é um aspecto importante no seu planejamento. Em seguida apresentaremos o software que escolhemos para nossa experimentação, bem como as atividades que foram aplicadas. 


\section{O software Geogebra e as retroações}

O Geogebra é um software de Matemática gratuito, com o qual podemos trabalhar com conteúdos de geometria, álgebra, gráficos, tabelas, estatística e cálculo. Nós o escolhemos, pois ele favorece a execução de atividades em duplas, ou trios, o que possibilita discussões entre os alunos durante a realização das atividades. Além disso, as retroações que este software oferece permitem ao estudante testar e validar, ou não, suas hipóteses e, com isso, alimentar ainda mais as discussões.

Por exemplo, ao pedirmos que o aluno faça a construção de um trapézio qualquer, ele tem várias possibilidades. Pode-se escolher o ícone polígono e marcar os quatros pontos sem utilizar as propriedades de um trapézio, escolhendo mais ou menos "a olho" o local dos vértices, como na Figura 1. Observe que temos a figura de um trapézio, mas como a construção não obedeceu às propriedades do quadrilátero, ao movimentar um dos vértices (Figura 2), o aluno perceberá que nem sempre sua representação manterá a forma que lhe foi solicitada construir.

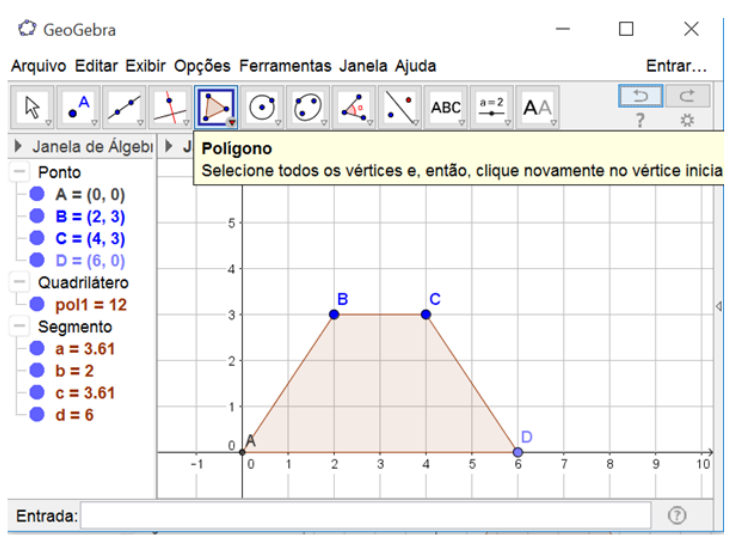

Figura 1

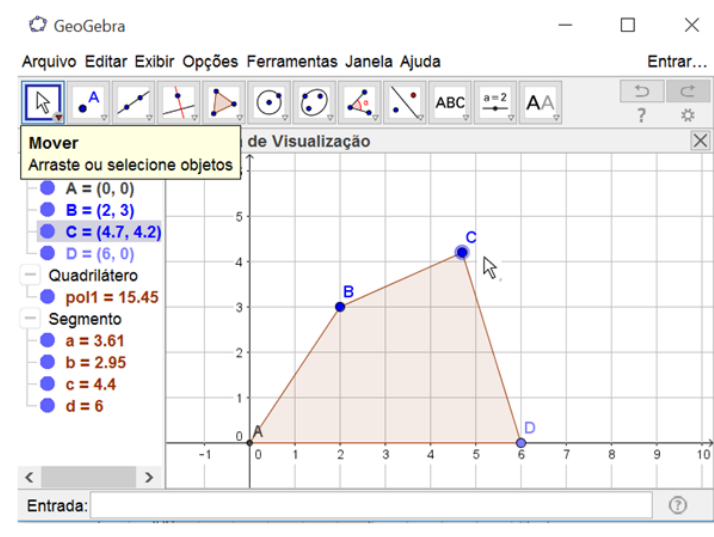

Figura 2

Essa possibilidade de movimentação das figuras construídas é uma das funcionalidades do software e que estamos chamando de retroações. São elas, que consideramos interessantes para as discussões. É importante destacar que essas escolhas se deram em função da nossa proposta em investigar possibilidades de cooperação entre estudantes. Desse modo, optamos por atividades que permitissem a discussão entre eles, como também um recurso tecnológico, no caso o software Geogebra, que favorecesse essa discussão, pois um espaço comunicativo é fundamental para que possa ocorrer momentos de cooperação.

Essas retroações do Geogebra são interessantes para a atividade na perspectiva de construção do conhecimento como um processo. Ela permite aos alunos trabalharem e irem testando suas hipóteses, já que eles mesmos podem ir verificando e discutindo o andamento e 
a correção da construção, com pouca ou nenhuma intervenção do professor. E, assim, proporcionar um ambiente favorável à cooperação.

Desta forma, escolhemos trabalhar com duas duplas de alunos da pós-graduação (três mestrandos e um doutorando) e a aplicação durou aproximadamente 50 minutos, e as atividades escolhidas foram:

1. Dados $\mathrm{AB}=10 \mathrm{~cm}$ e $\mathrm{AD}=\mathrm{CB}=5 \mathrm{~cm}$ : as medidas dadas na figura definem um único trapézio?

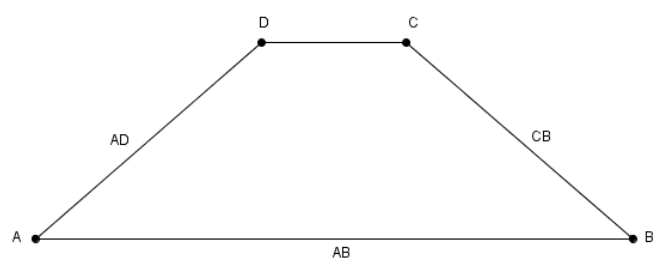

2. Se você prolongar os lados $\mathrm{AD}$ e $\mathrm{BC}$ esses lados se encontrarão em um ponto $\mathrm{E}$. $\mathrm{O}$ triângulo $\mathrm{ABE}$ é, neste caso, isósceles, equilátero ou escaleno? Esses resultados irão depender do quê?

3. Qual é a relação entre os ângulos de base (BÂD e $\mathrm{ABC})$ ? E BÂD e ADC?

\section{Nosso movimento de análise}

Assim que propomos a atividade, as duplas iniciaram a resolução. A dupla 01 Antônio e Miguel - apresentou, de início, a resolução através da construção de uma circunferência tal como detalhamos a seguir. Por outro lado, a dupla 02 - Ana e Clara se propôs a construir o trapézio indicado através de segmentos cujas medidas estivessem de acordo com a figura dada no enunciado. Nesse sentido, optamos por analisar os dados produzidos somente pela dupla 01 durante o momento de interação nas duplas. Em se tratando da discussão ao final da atividade, na qual a interação deu-se entre as duplas, trazemos a baila contribuições de todos os participantes.

Deste modo, percebemos, por meio do excerto a seguir, que assim que demos início a atividade, Miguel foi se articulando com sua dupla, Antônio, como poderiam resolver a atividade proposta, pensando na construção do trapézio com as medidas indicadas pela figura dada no enunciado.

Miguel: Aqui olha, poderia...Se você já estabeleceu esse ponto C... Foi o primeiro ponto que a gente estabeleceu?

Antônio: Sim.

Miguel: Podemos criar uma reta que é paralela a essa e que passa pelo ponto C...

Antônio: Sim

Miguel: Aí vai ser exatamente a base né?! [referindo-se a base BD do trapézio]
Antônio: hum...

Miguel: Então, nós podemos, pensar em desfazer. É... Então desfaz. Desfaz também o ponto $\mathrm{D}$, não é interessante?Ok!Só faz criar agora uma reta que passa aqui ó, no ponto $\mathrm{C}$ que é a...

Antônio: Reta perpend... não, reta paralela 
Neste primeiro momento, Miguel se mostra mais propositivo, expondo um modo de resolução para o qual Antônio parece concordar. Esta resolução refere-se à construção de duas circunferências de raio $5 \mathrm{~cm}$ e centro definido a partir dos pontos que definem o segmento base de medida $10 \mathrm{~cm}$.

Figura 03: Construção referente à atividade 01 da dupla 01

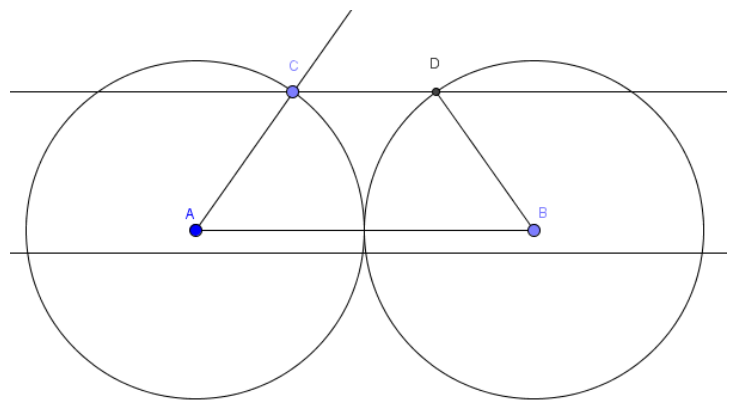

De acordo com Scherer (2005), para que ocorra cooperação é necessário habitar o ambiente do qual se está participando, agindo e operando com o outro e nesse sentido, quando Antônio completa a ideia de Miguel com relação à reta paralela, sugere que está envolvido neste jogo de reciprocidade, necessário para a cooperação. Assim, mesmo que anteriormente suas respostas tenham sido curtas e correspondentes às proposições de seu parceiro, o movimento de diálogo que poderia nos conduzir a uma ideia de colaboração, parece ser de cooperação de proposições iguais (PIAGET, 1973) e que, concordando sem ter nada mais a acrescentar, Antônio não se alongava em suas falas.

Indo ao encontro disso, ao finalizar a construção sugerida por Miguel, Antônio propõe outra maneira pela qual a atividade pode ser resolvida, de acordo com seu ponto de vista. O que corrobora com a ideia de que o tempo todo Antônio estava envolvido e acompanhando o raciocínio de seu parceiro nas proposições por ele realizadas, contudo, agora propõe outro modo,

Antônio: Dá para fazer diferente também...

Miguel: Sim...

Antônio: Eu estava pensando... Eu pensei numa coisa, mas eu não sei ao certo como fazer. Eu pensei em fazer uma altura aqui. Daria até para fazer uma animação e colocar ele aqui, por que isso independe né [referindo-se as medidas dadas pelo enunciado]! Ele pode ir e voltar e aqui também.

Miguel: Como assim ir e voltar?
Antônio: Não tem aquelas animaçõeszinhas que você faz aqui?

Miguel: tem... Que varia né, que varia. Mas você ia querer variar o que? A altura? Ou?

Antônio: A altura, varia a altura ele também vai variar ali, essa distância, dá para fazer só que... Miguel: Dá...

Antônio: Eu estou pensando agora como construir essa variação... 
A sugestão de Antônio era realizar uma construção na qual a altura do trapézio segmento perpendicular ao segmento $\mathrm{AB}$ passando pelo pondo $\mathrm{B}$ - variasse e que, assim, fosse possível animá-la. Nos momentos em que Antônio afirma que "ele pode ir e voltar e aqui também" e "... ele também vai variar ali..." sugerem que ele percebe que na construção anterior realizada a altura do trapézio varia, mas que agora gostaria de iniciar uma construção partindo disso e não mais da construção das circunferências, como anteriormente.

Como é possível observar, Miguel passa a querer entender o que seu colega propõe mostrando-se aberto a ouvir e compreender a ideia do outro num movimento dialógico no qual evidencia-se o respeito e a oportunidade de considerar e trabalhar com diferentes pontos de vista e ideias. Segundo Scherer (2005, p. 93) "a cooperação supõe a autonomia dos sujeitos envolvidos, ou seja, supõe a liberdade de pensamento, a liberdade moral e a liberdade política" e nesse sentido, acreditamos que, tanto Antônio quanto Miguel, estavam cooperando entre si.

Respeitante a atividade 02 , ocorreu o seguinte diálogo entre a dupla 01

Miguel: Então, a gente concorda que pode ser as três ocorrências?

Antônio: Sim

Perquisador1: Por que que pode ser as três? Miguel: Pela nossa construção, a gente...

Pesquisador 1: A construção de vocês...

Miguel: Volta lá, aqui olha! Esse triângulo aqui, nesse momento, ele é equilátero.

Antônio: 10 [comentando as medidas dos lados]...

Pesquisador1: E aí, você movimenta?!

Miguel: Passa a ser isósceles!

Pesquisador1: Tá...
Miguel: Agora o escaleno, o escaleno tem que...

Antônio: O escaleno não!

Miguel: Não, não pode ser escaleno!

Antônio: Só equilátero e isósceles. Escaleno teria que ter...

Miguel: Porque tem que ter o princípio de que... Né, as retas que formam esse triângulo, elas na verdade... O ponto de intersecção...

Antônio: Aqui né?!

Essas duas serão sempre iguais, essa aqui é fixa então!

Miguel: Exatamente!

Após ouvir a discussão que culminou na afirmação de que o triângulo, formado pelo prolongamento dos segmentos $\mathrm{AC}$ e $\mathrm{BD}$ (no caso da construção por eles realizada), poderia ser conforme movimentação tanto equilátero, quanto isósceles e escaleno o pesquisador 1 questiona o motivo. Na perspectiva de Piaget, questionamentos que provoquem desequilíbrio compõem o processo de construção de conhecimento, já que considerando a cooperação, dentre outras coisas, há intenção de interferir e até mesmo modificar as proposições feitas (SCHERER, 2005). E aqui, percebemos que, tanto o questionamento do pesquisador 1 quanto o software Geogebra, contribuíram para que os participantes refletissem e modificassem as afirmações realizadas. 
Notamos que, a partir do movimento realizado por Miguel no software, eles percebem a impossibilidade do triângulo em questão ser escaleno. $O$ que indica $o$ importante papel das retroações do Geogebra para a realização de determinadas construções, em específico, aquela que propomos. Não que não fosse possível propô-la nos moldes "lápis e papel", aliás, ao contrário. Porém, são propostas diferentes e para o caso do software, há possibilidade do movimento e exploração das ferramentas específicas as quais, portanto, implicam em um processo diferente.

No final da realização da proposta, discutiu-se com as duas duplas os diferentes modos de resolução da atividade que apareceram e, a partir deles, a definição de trapézio.

Pesquisador 1: Lados opostos paralelos... Então um trapézio pode ser paralelogramo? Porque... mexe esse ponto... O que acontece?

Antônio:Aqui ele vira um retângulo...

Pesquisador 2: Um retângulo é um trapézio?

Miguel: Não...

Ana: Sim...

Pesquisador2: Por quê?

Ana: Pra mim que é! Por que o trapézio tem que ser... tem que ter dois lados...

Miguel: E os outros dois assim...[referindo-se a inclinação do par de lados do trapézio não paralelos]

Clara: Mas o retângulo não é...
Ana: O retângulo pode ser... por que ele tem dois olha!

Pesquisador 1: O retângulo tem dois lados paralelos...

Ana: Tem dois...

Jéssica: Mas pra mim... pelo menos um?

Miguel: Os ângulos da base não podem ser retos... pra ser trapézio...

Ana: Pode...

Pesquisador 2: Qual é a definição?

Miguel: os ângulos da base não podem ser retos... que ai vai recair...

Ana: Mas existe...

"O questionamento presente na fala do professor precisa desequilibrar o aluno em relação às suas certezas, sendo capaz de gerar novos conflitos cognitivos." (SCHERER; BRITO, 2014, p. 58). Novamente percebemos aqui, a importância do professor em relação à provocação do desequilíbrio. Isso fica claro quando o pesquisador 1 questiona sobre a possibilidade de um retângulo ser um trapézio e o porque, exigindo que os participantes justificassem suas respostas.

Para Miguel, para ser trapézio era preciso que um dos lados do quadrilátero fossem paralelos e deste modo, infere que os ângulos da base não podem ser retos na tentativa de não incluir o retângulo na definição que estava propondo. Por outro lado, Ana tentava argumentar que em seu ponto de vista, para ser trapézio bastava que um dos dois pares de lados fossem paralelos. O outro par poderia ou não satisfazer essa condição. Temos assim, proposições contrárias as quais provocaram discussões entre os envolvidos, cada um tentando justificar seu ponto de vista na busca por um consenso. Scherer e Brito (2014) sublinham que estes tipos de 
proposições são importantes para estimular interrogações, dúvidas e busca. A exemplo disso, Clara, em meio a discussão, interroga: "pelo menos um?", referindo-se à quantidade de lados paralelos de um trapézio, pensando na definição. Por fim, quando Ana afirma que existem trapézios que ultrapassam a definição que Miguel estava a defender, trazendo o caso dos trapézios retângulos, coloca-o em desequilíbrio por não confirmar a certeza prévia tida em relação ao objeto.

Nesse sentido, Miguel repensa sua definição e mesmo diante das idas e vindas proporcionadas pela discussão, não concorda com a proposição defendida por Ana, na qual retângulos e quadrados, por exemplo, são trapézios. O que vai ao encontro do que Piaget (1977) escreve com relação às condições para que ocorra a cooperação. Ou seja, diante de uma afirmação, cada um deve justificar seu ponto de vista, seguindo a proposição que está a defender.

Para que ocorra a cooperação, é necessário que os envolvidos aceitem e respeitem as ideias do outro, diferentemente da tolerância. No trecho abaixo, fica evidente que, apesar de continuar a defender sua proposição, Miguel ouve o argumento de Ana e passa a concordar com sua colega

Miguel: Ah, então aqui... Esse aqui também... Isso aqui é um escaleno né [referindo-se ao trapézio escaleno]... Perfeito! Concordo então que também existe essa possibilidade...

Ana: Ese eu considerar a área vai dar também... Pesquisador2: Por quê?

Ana: Eu digo, a fórmula da área. Se fizer no paralelogramo vai dar certo... É porque eu já fiz isso... [em outros momentos] se eu podia aplicar a fórmula do retângulo e deu certo, mas eu não sei...
[...]

Miguel: Pra mim o que fica é esses dois lados aqui paralelos...

$[\ldots]$

Ana: É! Se eu pegar retângulo, base vezes altura. Mas se eu pegar e aplicar trapézio, também vai dar certo! Porque vai cortar e cortar... no final vai ficar base vezes altura...[referindo-se a utilizar a fórmula da área do trapézio no retângulo].

$\mathrm{Na}$ sequência da discussão Ana busca na fórmula do cálculo da área das figuras planas envolvidas argumentos para defender sua proposição, contrária a de Miguel. Isso tudo ratifica nosso pressuposto de que ouve um movimento de cooperação entre os participantes da pesquisa.

Neste momento, Miguel, Antônio e Clara concordavam com a definição 01 e Ana insistia em defender a definição 02. Nenhum deles propôs a busca de informações outras em livros ou internet. Sendo assim e também por limitações relativas ao tempo, os pesquisadores realizaram uma pequena institucionalização da atividade expondo que 
as duas definições são válidas. Entretanto, uma vez assumida uma delas, todas as implicações decorrentes devem ser coerentes para com o conceito assumido.

\section{Algumas considerações}

Nos propomos a realizar uma discussão acerca de cooperação, segundo Piaget, a partir da análise de uma situação envolvendo a definição de trapézio. Desta forma, temos algumas considerações com relação às atividades, ao software Geogebra e, por fim, à análise que fizemos.

Quanto às atividades percebemos que favoreceram a discussão por nós objetivada, pois embora parecesse simples do ponto de vista da execução, revelou-se complexa a partir das questões que foram surgindo dela. Além disso, os questionamentos dos pesquisadores foram fundamentais para provocar e alimentar o debate. Apesar de os participantes terem realizado as questões 02 e 03, em função do tempo, não foi possível abordá-las na discussão final o que evidencia que nem sempre o quantitativo de atividades é relevante perante as discussões que se pretende fazer e que podem surgir no andamento da atividade.

Ainda sobre isso, inferimos que as atividades podem ser aplicadas em outro contexto, como, por exemplo, com alunos do ensino fundamental e/ou médio. No entanto isso irá depender dos objetivos tidos pelo professor. Ele é quem conhece seus alunos e poderá pensar na possibilidade de implementação, já que esta depende de vários fatores, tais como conhecimento do software e de certos conceitos que as atividades exigem conhecer, etc. No entanto, nada impede que se realizem adaptações de acordo com o contexto.

O software Geogebra também contribuiu com nosso objetivo, pois com seu uso os participantes realizaram as construções, mexendo, puxando, movimentando. Em alguns momentos, essas retroações foram fundamentais para que os participantes revissem suas certezas com relação às afirmações realizadas.

A partir da análise que fizemos, acreditamos que a dupla 01 estava vivenciando um processo de cooperação. Consideramos ainda que no momento final de discussões entre as duplas, também houve um movimento cooperativo o qual foi possível devido à junção de diversos fatores. A saber: as atividades elaboradas no software com vistas ao objetivo; os participantes que se envolveram com a proposta e o tempo todo mostraram-se abertos à discussão e os pesquisadores que, na medida do possível, realizaram intervenções no sentido de provocar o desequilibro e mais debates. 


\section{Referências}

PONTE, J. P.; OLIVEIRA, H.; VARANDAS, J. M. O contributo das tecnologias de informação e comunicação para o desenvolvimento do conhecimento e da identidade profissional. In: FIORENTINI, D. (Org). Formação de professores de Matemática. Campinas, SP: Mercado Letras, 2003.

SCHERER, S. Uma estética possível para a educação bimodal: aprendizagem e comunicação em ambientes presenciais e virtuais. 2005. 240f. Tese (doutorado em Educação: currículo). Pontifícia Universidade Católica de São Paulo, São Paulo, 2005. p.86-100.

SCHERER, S.; BRITO, G. da S. Educação a distância: possibilidades e desafios para a aprendizagem cooperativa em ambientes virtuais de aprendizagem. Educar em Revista, Curitiba, Brasil, Edição Especial n. 4/2014, p. 53-77. Editora UFPR.

VAlente, J. A. (Org.) O Computador na Sociedade do Conhecimento. Campinas, SP: UNICAMP/NIED, 1999.

VALENTE, J. A. A Espiral de Aprendizagem: O processo de Compreensão do Papel das Tecnologias de Informação e Comunicação na Educação. Tese (Livre Docência) Universidade Estadual de Campinas, Campinas, SP, 2005.

PIAGET, J. A tomada de consciência. Tradução por Edson Braga de Souza. São Paulo: Melhoramentos, 1977. 